\title{
Tensiometry as a Simple Analytical Method for Quantification of Solubility and Release of Aroma Molecules in Aqueous Media
}

\author{
Ruth Kudla ${ }^{1}$, Jochen S. Gutmann ${ }^{1,2,3}$ (D) and Larisa A. Tsarkova $1,2,4, * \mathbb{D}$ \\ 1 Germain Textile Research Center North-West (DTNW), 47798 Krefeld, Germany; \\ ruth.kudla@currenta.biz (R.K.); jochen.gutmann@dtnw.de (J.S.G.) \\ 2 Physical Chemistry, University Duisburg-Essen, 47057 Duisburg, Germany \\ 3 Center for Nanointegration Duisburg-Essen (CENIDE), 45141 Essen, Germany \\ 4 Department of Chemistry, Moscow State University, 119991 Moscow, Russia \\ * Correspondence: tsarkova@dtnw.de or tsarkova@colloid.chem.msu.ru
}

check for

updates

Citation: Kudla, R.; Gutmann, J.S.;

Tsarkova, L.A. Tensiometry as a

Simple Analytical Method for

Quantification of Solubility and

Release of Aroma Molecules in

Aqueous Media. Molecules 2021, 26,

7655. https://doi.org/10.3390/

molecules26247655

Academic Editor: Piotr

Paweł Wieczorek

Received: 15 November 2021

Accepted: 15 December 2021

Published: 17 December 2021

Publisher's Note: MDPI stays neutral with regard to jurisdictional claims in published maps and institutional affiliations.

Copyright: (C) 2021 by the authors. Licensee MDPI, Basel, Switzerland. This article is an open access article distributed under the terms and conditions of the Creative Commons Attribution (CC BY) license (https:// creativecommons.org/licenses/by/ $4.0 /)$.

\begin{abstract}
Dynamic tensiometry is shown to be a high-potential analytical tool in assessing physicochemical characteristics of fragrance molecules, such as solubility limit, volatility as well as much rarely assessed interfacial activity of these amphiphilic molecules. Surface tension of aqueous solutions of selected essential oils has been measured as a function of time and fragrance concentration using maximum bubble pressure method. The effect of the temperature and saline solution on the rate of dissolution in water was assessed. Dynamic surface tension turned to be sensitive to the composition of fragrances, as demonstrated on examples of natural and synthetic mixtures. Furthermore, presented work reveals the possibility of maximum bubble pressure tensiometry method to quantify the amount of fragrance compositions in flavored salts, including the artificially aged carrier samples. Suggested here analytical approach can be used for the detection of the purity of essential oils, for the optimization of compositions and of the manufacturing processes of fragrances-containing products, as well as for the assessment of the release/evaporation of fragrances from carrier systems.
\end{abstract}

Keywords: essential oils; monoterpens; surface activity; solubility in aqueous media; dynamic tensiometry; fragrance carrier

\section{Introduction}

Perfumes, besides being noble products themselves, are often added as components to the products in cosmetic, textile, wellness or home-care branches in order to add a superior quality and thus to influence the consumer behavior. Accordingly, intensive research is dedicated to the understanding of the olfactory and other biological functions of perfume molecules [1,2]. In research and development of fragrances-containing products, odor assessment is usually performed by human olfactory system or by gas chromatography, as well as by chemo- or bio-electronic sensing devices [3-5].

Essential oils are generated through different biosynthetic routes and extracted from vegetable raw materials. The variety of odor compounds is represented by aliphatic or aromatic amphiphilic molecules with varied carbon backbones and diverse functional groups, including aldehydes, esters, ketones, alcohols, alkenes, carboxylic acids, amines. Recent research indicates, that rich and complex compositional variability of these poorly water soluble volatile amphiphiles defines their specific surface-active properties which can be assessed with tensiometry methods [6,7]. However, so far their intrinsic amphiphilic properties have not been thoroughly considered from the physico-chemical and analytical point of view, so that the research in this field is in its infancy.

Surface tension of aqueous solutions depends on the adsorption of a solute at the liquid-vapor interface [8]. This process, however, is time-dependent. Most studies of the 
surface tension focus on the equilibrium conditions, i.e., on the maximum surface coverage which is typically achieved on the time scale of tens of minutes to hours. More relevant to technological processing and, presumably, to the functions in biological systems is the dynamic surface tension, i.e., an ability of an amphiphile to decrease surface tension of aqueous solutions at a time scale of milliseconds and below [9-11]. A revealed distinctive feature of fragrance molecules, which can be considered as volatile amphiphiles, is their high dynamic interfacial activity, much higher than that of conventionally used technical surfactants [6]. Another potentially useful property of such amphiphiles is their volatility, so that they notably evaporate from interfaces. Accordingly, the surface tension of their aqueous solutions increases on a time scale of minutes. Monitoring the increase of the surface tension allows evaluating of the evaporation rate and of the material constant, which turned to be specific to the chemistry of the aroma molecules [12]. Further development of the proposed analytical approach concerns the possibility to evaluate molecular interactions of aroma molecules with other components of complex formulations, such as surfactants, polymers, salts and pigments [13], as well as the release of fragrances from carrier systems, which typically represent multicomponent, heterogeneous systems such as emulsions [14-16], foams [17], capsules [18], liposomes [19,20], latexes [21], surfactant solutions [13,22-24] or from smart cleavable surfactant profragrances [25].

In this work dynamic tensiometry, i.e., the assessment of the time evolution of the surface tension, is shown to be a useful analytical tool in evaluating quantitative physicochemical characteristics of fragrance molecules, such as solubility limit, volatility, and interfacial activity. We first present surface tension of aqueous solutions of selected essential oils, which has been measured continuously during saturation process to determine the solubility limit. Then we discuss the sensitivity of the surface tension to the fragrance concentration, the composition of natural and synthetic mixtures as well as to external factors such as water salinity and temperature. Finally, the possibility of the maximum bubble pressure method to quantify the amount of fragrance molecules in flavored salts, including artificially aged carrier samples, is demonstrated. This method can be considered as a valuable complementary analytical tool to assess structural and compositional heterogeneity, chemical aging, molecular interactions of aroma molecules in technologies related to isolation and usage of essential oils and fragrances.

\section{Results and Discussion}

\subsection{Dynamic Surface Tension of Saturated Solution of Essential Oils}

Figure 1 shows the curves of the surface tension versus life-time $\left(t_{\text {life }}\right)$ of saturated solutions of indicated fragrances, among others of monoterpene alcohols, which are typically poorly soluble in water (Table 1). As clearly seen, almost all studied solutions already in a millisecond range exhibit a significant reduction of the surface tension as compared to that of pure water, which is time-invariant. The rapid reduction of the surface tension of water is an indication of the fast diffusion and adsorption of a solute at water-air interface. We note that this fast adsorbing behavior is a remarkable feature of poorly soluble aroma molecules as compared to conventional technical surfactants, as well as to the solutions of highly soluble short-chain alcohols [6].

Each measured curve exhibits a decrease in the surface tension with increasing the surface life-time $\left(t_{\text {life }}\right)$, until time-invariant values are reached, e.g., for monoterpene alcohols geraniol, nerol and linalool. As also seen in Figure 1, the surface activity of alcohols is higher than that of fragrance compounds with an aldehyde group (citronellal and citral) since the former provide a more fast and effective decrease of the surface tension. This effect cannot be entirely attributed to the respective solubility of the aroma molecules in water, i.e., to the concentration of the measured saturated solutions (Table 1). Saturated solutions of the monoterpenes nerol, geraniol and linalool show similar kinetics of the surface tension, despite large differences in solubilities $(1.45 \mathrm{~g} / \mathrm{L}$ for linalool and practically insolubility for nerol). 


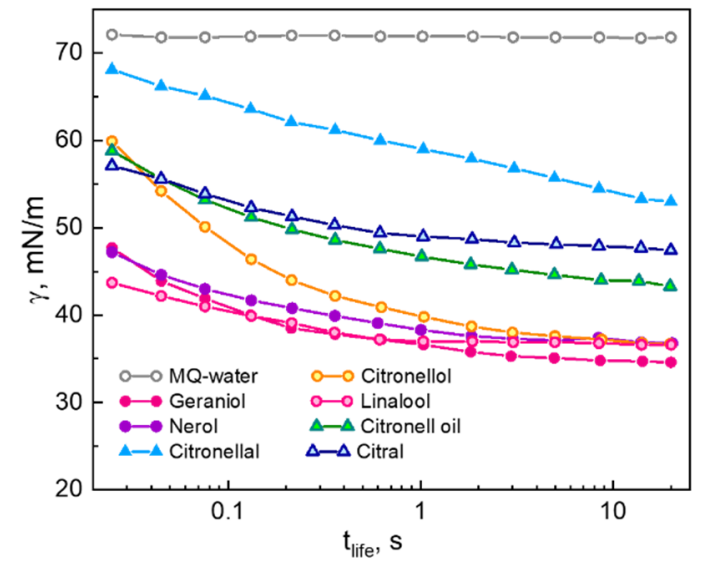

Figure 1. Surface tension versus surface lifetime $\left(t_{\text {life }}\right)$ of water and of saturated solutions of indicated essential oils/aroma molecules (Table 1).

Table 1. Physicochemical properties of studied aroma molecules.

\begin{tabular}{|c|c|c|c|c|c|}
\hline $\begin{array}{c}\text { Volatile } \\
\text { Amphiphile }\end{array}$ & Purity (GC)\% & $\begin{array}{l}\text { Molecular Weight, } \\
\text { g/moL }\end{array}$ & $\begin{array}{c}\text { Solubility in } \\
\text { Water at } 20^{\circ} \mathrm{C} \mathrm{g} / \mathrm{L}\end{array}$ & $\begin{array}{c}\log P^{b} \text { at } \\
20^{\circ} \mathrm{C}\end{array}$ & $\begin{array}{c}\text { Boiling Point, } \\
{ }^{\circ} \mathrm{C}\end{array}$ \\
\hline Geraniol 98 & 98.7 & 154.25 & 0.686 & 3.28 & $229-230$ \\
\hline Nerol & 98.9 & 154.25 & - & 3.56 & $224-225$ \\
\hline Linalool & 98.8 & 154.25 & 1.45 & 2.44 & 198-200 \\
\hline Citronellol & 96.8 & 156.27 & - & 3.91 & 224 \\
\hline Citronellal & 98.8 & 154.25 & 0.07 & 3.53 & 208 \\
\hline Citral & 97.8 & 152.23 & 0.42 & 2.33 & 225 \\
\hline Citronell oil & $\begin{array}{l}\text { Geraniol (25-45\%) and } \\
\text { Citronellal (25-54\%), Citral, } \\
\text { Eugenol and Vanillin }\end{array}$ & 154.25 & - & - & $208-230$ \\
\hline $\begin{array}{l}\text { Cis-3Hexenyl } \\
\text { acetate }\end{array}$ & 98.6 & 142.20 & 11.1 & 1.77 & 172 \\
\hline
\end{tabular}

Furthermore, saturated solution of insoluble in water citronella oil, which is a natural multicomponent mixture of geraniol, citronellal and citral (Table 1), is also characterized by a reduced surface tension already in the millisecond range.

These examples, on one side, demonstrate molecular-structure defined differences in the amphiphilicity and, accordingly, in the surface activity of the aroma molecules, which can be systematically studied using low-cost and high throughput tensiometry methods. On the other side, this analytical method can be used to verify available in data-bases values of molecular solubility of essential oils. Establishing "Structure-property relationship" of such aroma molecules with regards to their molecular structure, volatility and interfacial activity is envisaged to be an exciting and application-relevant research direction where an interdisciplinary collaboration of synthetic, analytical and biochemistry scientists may result in new insights and applications. Importantly, the concentration of a fragrance in the interfacial layer is directly linked to its concentration in the vapor phase, which suggest a possibility to correlate tensiometric and head-space chromatography measurements.

It should be noted, that the measurement geometry of the MBP method (a smallvolume air bubble in a large-volume solution) is particularly suitable for the assessment of the interfacial behavior of volatile amphiphiles in comparison with static (equilibrium) tensiometric methods. In Pendant drop or Wilhelmy Plate tensiometry methods an exposure of extended interface to the environment may result in the uncontrolled evaporation of the volatile amphiphile, causing the surface tension to increase with time [26]. 
We believe that high interfacial activity of perfumes in aqueous solutions can be attributed to the existence of mesoscale solubility [27]. According to Rak and Sedlak [27], mesoscale structures in aqueous solutions of organic liquids are not-fluctuating objects with macroscopic lifetimes and near-spherical shapes with radii in the range $30-300 \mathrm{~nm}$. These aggregates provide a high local concentration of a solute, also in the vicinity of the interface. Accordingly, an increase an effective diffusion coefficient results in the observed fast-adsorbing behavior.

\subsection{Kinetics of Solution Saturation under Variation of the Temperature and Presence of the Salt}

Saturated solutions of the studied aroma molecules have been prepared by adding an excess of the organic phase to water followed by continuous stirring to achieve saturation with molecularly dissolved aroma molecules. The dissolution process has been monitored by taking an aliquoted of the water phase in $5 \mathrm{~min}$ intervals for the surface tension measurements. As exemplarily shown in Figure 2a for geraniol solution, the shape of the kinetic curves does not change with the saturation time, with the upper curve taken after 5 min and the lower curve (solid symbols) measured after 70 min of saturation being similar. The curves just appear shifted along the Y-axis to the lower values of the surface tension. The decrease of the surface tension is due to the growth of the molecular concentration in solution, which simultaneously leads to a higher adsorption at the air-water interface and. Before each measurement, the solutions were filtered through a polyether sulfone filter (with a pore size of $500 \mu \mathrm{m}$ ) to remove excess oil droplets from the solution and to achieve a good reproducibility of the surface tension measurements using MBP method.
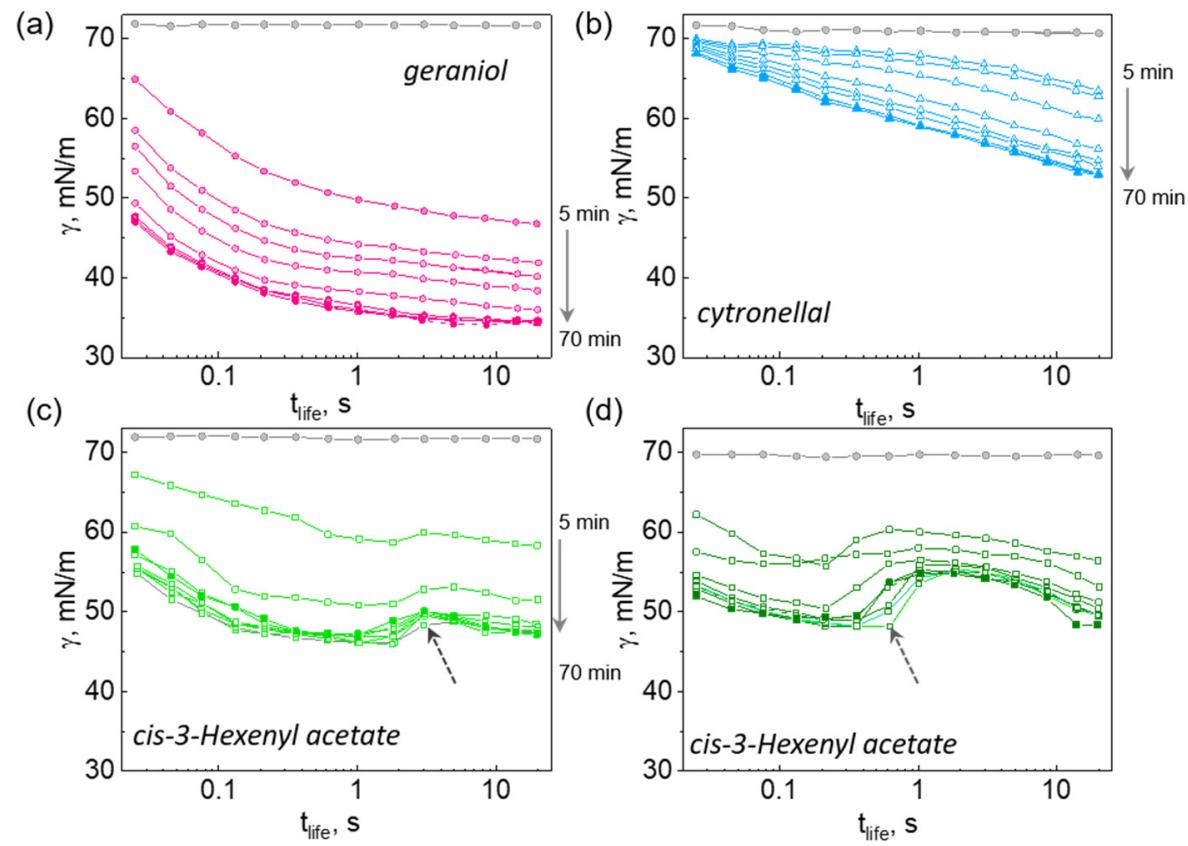

Figure 2. Dynamic curves of the surface tension versus surface life-time $\left(t_{\text {life }}\right)$ measured at $25{ }^{\circ} \mathrm{C}(\mathbf{a}-\mathbf{c})$ and at $40{ }^{\circ} \mathrm{C}$ (d) for water (gray curves in all plots), geraniol (a), citronellal (b) and cis-3-Hexenyl acetate solutions during the saturation process. Shown curves have been measured after $5 \mathrm{~min}$ up to 70 min of saturation with 5 min intervals. Gray dashed arrows in (c,d) point to the curves taken at $25 \mathrm{~min}$ saturation time. Solid symbols in each plot indicated solutions after $70 \mathrm{~min}$ of saturation.

The dynamic surface tension of solutions of citronellal (Figure 2b) differ from that of geraniol both in the shape of the curves versus surface life time $\left(t_{\text {life }}\right)$ and in their evolution with the saturation time. In particular, the drop of the surface tension in the ms range is not so pronounced as for monoterpene alcohols, and the equilibrium (time-independent) values of the surface tension are not achieved in a lapse time of $10 \mathrm{~s}$ of the measurement. This 
observation suggests a strong diffusion-limited adsorption process of citronellal molecules at the surface.

Shown in Figure 2c,d is the dynamic surface tension of solutions of cis-3-Hexenyl acetate during saturation and measurement at $25^{\circ} \mathrm{C}$ (Figure $2 \mathrm{c}$ ) and $40{ }^{\circ} \mathrm{C}$ (Figure 2d). The non-trivial shape of the curves can be explained by a presence of solutes with different diffusivity and interfacial activity, i.e., the kinetic curves are indicative to the purity/composition of the oil. The initial steady decrease of the surface tension up to $t_{\text {life }}$ of ca $0.4-0.5 \mathrm{~s}$ and ca $2 \mathrm{~s}$ in Figure 2c,b, respectively, is due to adsorption of a faster and a more surface-active component, which is on a longer time-scale is replaced from the interfacial layer by a slower/less surface-active component. This replacement may be the result of a faster evaporation behavior of the former. Another possible explanation, is the "reaction"- driven interfacial behavior [28], when adsorbed molecules of cis-3Hexenyl acetate undergo a phase transition from molecular to condensed state, resulting in a "mosaic"-like structure within the interfacial layer. This may lead to an effective increase of the area per molecule, and hence to temporal increase of the surface tension, which returns to the low value as more molecules reach the interfacial layer.

Interestingly, the time-scale of the surface tension modulation appears to be dependent both on the temperature of the dissolution/measurements (compare Figure 2c,d), and on the kinetics of the dissolution/extraction into the water phase. As indicated by dashed arrows in Figure $2 \mathrm{c}, \mathrm{d}$, the lowest surface tension at $t_{\text {life }}$ of about second is achieved not for a saturated solution, but for a solution which was extracted in $25 \mathrm{~min}$. On the other hand, at a time scale of tens of seconds, the lowest surface tension is exhibited by fully saturated solutions. It should be noted, that since aroma molecules can desorb from the interface into the gas phase, tiny differences in the values of the saturated vapor pressure may affect the composition of the interfacial layer, i.e., the values of the surface tension. A quantitative evaluation of such non-trivial behavior of the dynamic surface tension is beyond the scope of the current study.

Generally, a calibration curve (isotherm) can be generated and used to determine unknown concentrations of a solute in test solutions $[6,26]$. The concentration at which the minimum value of the surface tension is achieved according to the calibration curve (isotherm) presumably indicates the limit of the molecular solubility of the investigated substance. This data can be and compared with the solubility data, which is available in literature (Table 1). The discrepancy observed in our study (e.g., for citronella oil and nerol) presumably can be explained by the existence of the mentioned above "meso-aggregates" of organic liquids in water [27]. These aggregates may lead to the fast-adsorbing behavior at the interface.

Figure 3 summarizes measurements, which are presented in Figure 2a,b for geraniol and citronellal, and for some other selected essential oils. It displays for indicated substances the surface tension at $t_{\text {life }}$ of $20 \mathrm{~s}$, as well as the time needed to achieve saturation as a function of the temperature of the saturation/measurement and of the presence of salt (physiological solution). While the quasi-equilibrium surface tension of monoterpene alcohols is more or less invariant to the molecular structure and solution temperature/presence of salt, as follows from the strong deviations in the saturation time, the diffusion and adsorption activity is clearly dependent on the molecular and environmental features. These observations are in agreement with the earlier studies, which emphasized the importance of molecular mobility (translational diffusion and mass transfer through phases) of volatile compounds on their release from the matrix [29].

Although the understanding of scientific basics behind these differences (or similarities) in the interfacial adsorption of aroma molecules is still to be elaborated, the data in Figures 3 and 4 clearly shows that tensiometric measurements have a high sensitivity with regards to the concentration as well as to cumulative compositional heterogeneity of essential oils in aqueous solutions. We believe that combining tensiometry with other analytical methods, which quantify the molecular structure of the solutes, will advance the methods of isolation, purification and characterization of plant-based substances. 


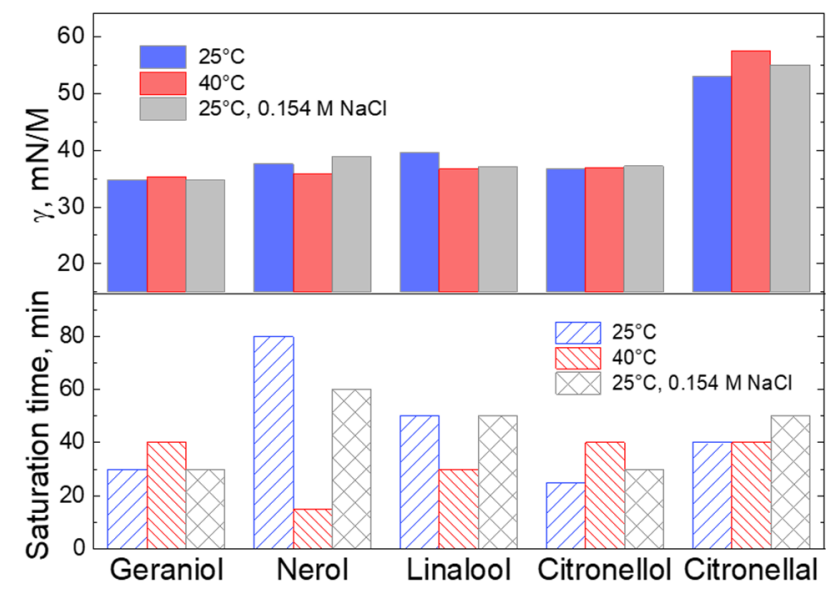

Figure 3. Summary of the surface tension at a $t_{\text {life }}$ of $20 \mathrm{~s}$ (top panel) and of the dissolution time (bottom panel) for indicated substances, evaluated at $25^{\circ} \mathrm{C}$ in Milli-Q water and in salinity solution $(0.154 \mathrm{M} \mathrm{NCl})$ and at $40{ }^{\circ} \mathrm{C}$.
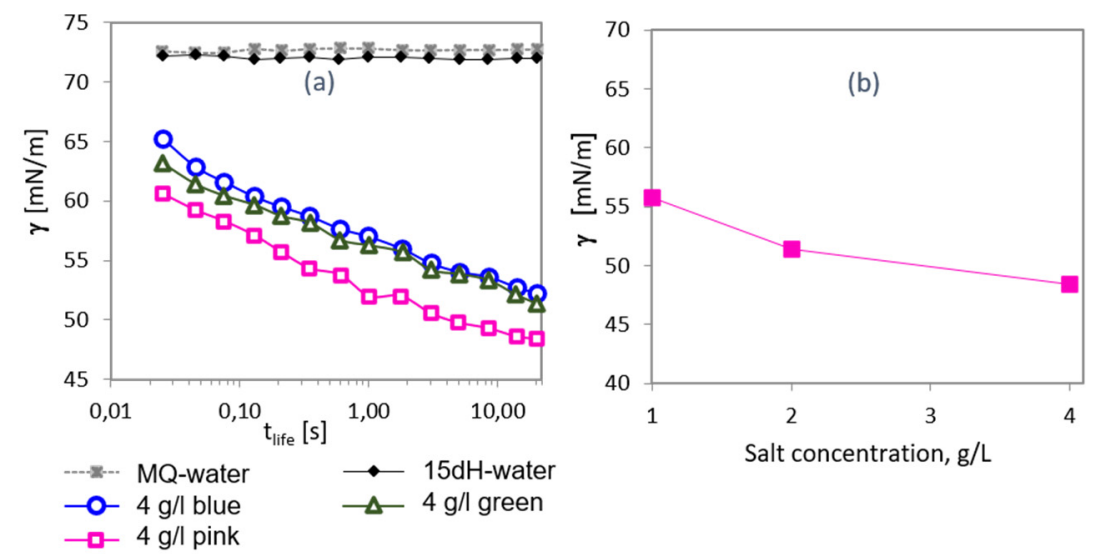

Figure 4. (a) Surface tension of water (grey symbols), synthetic water with a water hardness of $15^{\circ} \mathrm{dH}$ (black symbols) and of solutions of three flavored salts each with a concentration of $4 \mathrm{~g} / \mathrm{L}$ (pink, green and blue symbols, respectively) versus surface life-time $\left(t_{\text {life }}\right)$. (b) Surface tension (at $20 \mathrm{~s}$ surface life-time) of pink salt solutions versus concentration in the solution.

\subsection{Assessment of the Fragrance Load and Carrier Aging}

Demonstrated surface activity of aroma molecules was used to analyze flavored salt products, which apparently differ in color and in composition of loaded fragrances. Figure 4a shows kinetic curves of the solutions of pink, green and blue salts, as well as the surface tension of water with a hardness of $15^{\circ} \mathrm{dH}$. While it is well known that salts do not decrease the surface tension of water, the dissolved fragrances have a clear influence on the surface tension. We note, that flavored salt apparently has been loaded with different fragrance compositions, so that the solutions and interfacial layers contain mixtures of aroma molecules rather than individual substances. As exemplary shown in Figure $4 \mathrm{~b}$ for a pink flavored salt, the higher the concentration of the dissolved fragrance carrier, the lower is the surface tension at $20 \mathrm{~s} t_{\text {life }}$, i.e., the higher is the adsorbed amount of fragrances in the interfacial layer.

The examined salts have been fractionated into coarse and fine (less than $1 \mathrm{~mm}$ ) fractions. Figure $5 \mathrm{a}, \mathrm{b}$ shows the surface tension at $20 \mathrm{~s} t_{\text {life }}$ of the solutions of pink and green salts as a function of the salt concentration in the solution for fine and coarse fractions. It can be seen, that dissolving of the fine salt fraction leads to a stronger decrease in the surface tension. This observation implies that in this case a larger amount of fragrance is released in the solution. Since the fine fraction has a larger surface area than a coarse 
fraction of the same mass, it can be concluded that the fragrances are loaded onto the surface of the salts grains.
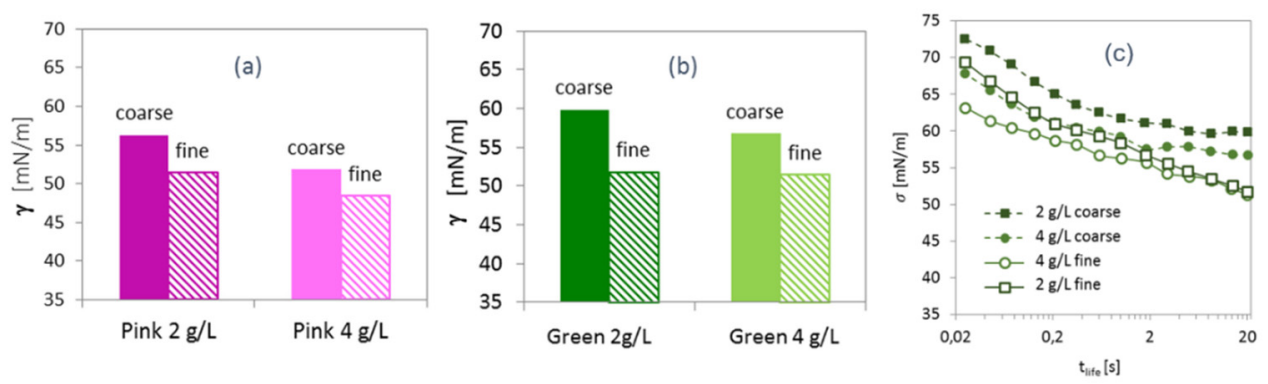

Figure 5. (a,b) Surface tension (at $20 \mathrm{~s}$ surface-life time) of the solutions of coarse and fine fractions of pink (a) and green (b) salts with concentrations of $2 \mathrm{~g} / \mathrm{L}$ and $4 \mathrm{~g} / \mathrm{L}$. (c) Surface tension versus surface-life time $\left(t_{\text {life }}\right)$ of solutions of coarse and fine fractions of the green salt with a concentration of $2 \mathrm{~g} / \mathrm{L}$ and $4 \mathrm{~g} / \mathrm{L}$.

Additional information can be gained from the consideration of the dynamic curves of the surface tension, which are presented in Figure $5 \mathrm{c}$ for green salt solutions. Increasing the amount of the dissolved coarse fraction from 2 to $4 \mathrm{~g} / \mathrm{L}$ leads to the increase of the dissolved fragrance composition in solution, as reflected in a lower surface tension of the latter solution. However, dissolving a larger amount of the fine fraction of the green salt $(4 \mathrm{~g} / \mathrm{L})$ does not lead to a further decrease in the surface tension (at $20 \mathrm{~s}$ surface life-time) as compared to the solution with $2 \mathrm{~g} / \mathrm{L}$ salt concentration. Although these two curves show clear differences in the range of $t_{\text {life }}$ below second, the amount of the loaded fragrance, presumably, exceeds the solubility limit in water, so that the excess of fragrances in $4 \mathrm{~g} / \mathrm{L}$ solution is likely dissolved in a form of mesoscale oil droplets.

Such simple and high throughput tensiometry method can also be used to evaluate the ageing of products containing aroma molecules. To demonstrate this, the pink salt was artificially aged by storing under exhaust snorkel with a defined exhaust air rate of $1 \mathrm{~m}^{3} / \mathrm{h}$ for $24 \mathrm{~h}$. Figure 6 shows the surface tension of the solutions of the original and of the artificially aged pink salt. The surface tension of the solutions from the aged salt is higher than that of respective solution from the fresh product. As mentioned above, by establishing a calibration curve (isotherm) of the used fragrance composition it is possible to evaluate quantitative information regarding the concentration decrease (and respective loss of the product quality) and accordingly to develop recommendations on the optimal storage of the product.

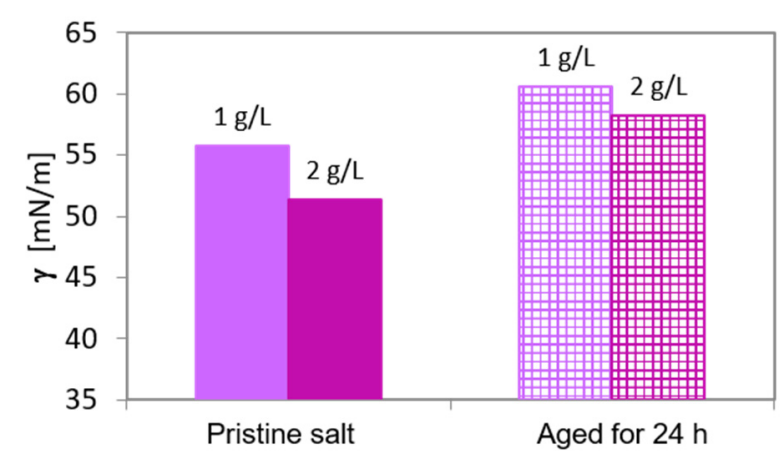

Figure 6. Surface tension (at $20 \mathrm{~s}$ surface life-time) of pink salt solutions with a concentration of 1 and $2 \mathrm{~g} / \mathrm{L}$ before and after artificial aging for $24 \mathrm{~h}$.

\section{Materials and Methods}

Aroma molecules (Table 1) have been provided by NHU Europe GmbH (Bardowick, Germany). Flavored salts with pink, blue and green colors (DPC spa, Gorla Minore, Italy) 
have been used as received. Solutions have been prepared using Milli-Q purified water or $0.9 \% \mathrm{NaCl}$ (from Aldrich, St. Louis, MO, USA) solution.

Surface tension $\gamma$ was measured using maximum bubble pressure (MBP) tensiometer "Sita pro line t100" (SITA GmbH, Dresden, Germany) with a capillary made of polyether ether ketone (PEEK). With this method dynamic surface tension at air-water interface can be determined as a function of the age of a newly formed surface with great accuracy from a few tenths of a millisecond to hundreds of seconds. Air bubble is formed at the end of the capillary, which is immersed in a testing solution, and its internal pressure changes continuously as the radius grows (see Figure 7). The surface tension is calculated from the difference between the maximum and minimum pressures in each air-bubble formation process. We note that surface active molecules (surfactants) are typically characterized at equilibrium adsorption conditions (at infinite surface age) using so-called static tensiometry methods.

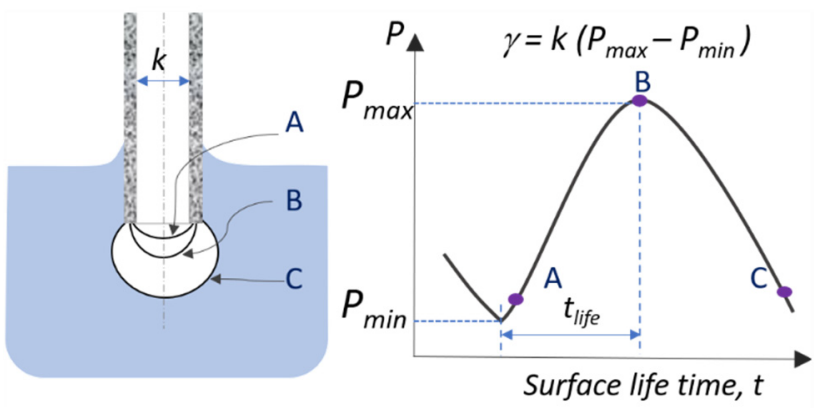

Figure 7. Schematic representation of the measuring principle of the maximum bubble pressure (MPB) method for the measurements of the dynamic surface tension $\gamma$ of aqueous solutions. The surface tension is calculated from the measurement of the pressure difference $\left(P_{\max }-P_{\min }\right)$ in the bubble in a capillary with a known radius $1 / 2 \mathrm{k}$, as indicated.

Saturated solutions of the studied aroma molecules have been prepared by adding an excess of the organic phase to MilliQ-purified water followed by continuous stirring using a magnetic stirrer to facilitate the diffusion of aroma molecules. Measurements of the surface tension have been performed at temperatures of $25 \pm 0.5^{\circ} \mathrm{C}$ and at $40 \pm 0.5^{\circ} \mathrm{C}$.

\section{Conclusions}

Demonstrated here surface tension measurements expand the tool of analytical methods, traditionally applied to characterize fragrances. Using maximal bubble pressure method it is possible to assess physico-chemical characteristics of fragrance molecules, such as solubility limit, volatility as well as the interfacial activity of these amphiphilic molecules. Establishing "structure-property relationship" of such aroma molecules with regards to their molecular structure, volatility and interfacial activity is envisaged to be an exciting and application-relevant research direction. Importantly, the concentration of a fragrance in the interfacial layer is directly linked to its concentration in the vapor phase, which suggest a possibility to correlate tensiometric and head-space chromatography measurements.

As an application example, aqueous solutions of three differently colored carrier salts with different loaded fragrance compositions have been studied using dynamic tensiometry. The fraction of the carrier (coarse/fine) and the amount of the dissolved flavored salts has been varied. Additionally, the effect of the artificial aging on the amount of the loaded aroma molecules has been revealed. The demonstrated approach can be used for the optimizations of compositions and of the manufacturing processes of fragrancescontaining products, as well as for the assessment of the release/evaporation of fragrances from the products.

Further development of the proposed approach will make it possible to evaluate the molecular interactions of aroma substances with other components of detergents and of cosmetic formulations, such as surfactants, polymers, salts and pigments. 
Author Contributions: Conceptualization, L.A.T.; methodology, R.K.; resources, J.S.G.; writingoriginal draft preparation, R.K.; writing—review and editing, L.A.T.; project administration, L.A.T.; funding acquisition, L.A.T. and J.S.G. All authors have read and agreed to the published version of the manuscript.

Funding: Support by the Open Access Publication Fund of the University Duisburg-Essen is gratefully acknowledged. L.T. appreciates the financial support by the Russian Foundation for Basic Research (RFBR) according to the research project № 20-53-18008.

Institutional Review Board Statement: Not applicable.

Informed Consent Statement: Not applicable.

Data Availability Statement: Not applicable.

Acknowledgments: NHU Europe GmbH (Bardowick, Germany) is kindly acknowledged for donating samples of essential oils for experiments. DPC spa (Gorla Minore, Italy) is acknowledged for providing flavored salts.

Conflicts of Interest: The authors declare no conflict of interest.

Sample Availability: Samples of the compounds are not available from the authors.

\section{References}

1. Firestein, S. How the olfactory system makes sense of scents. Nature 2001, 413, 211-218. [CrossRef]

2. Wolf, S.; Jovancevic, N.; Gelis, L.; Pietsch, S.; Hatt, H.; Gerwert, K. Dynamical Binding Modes Determine Agonistic and Antagonistic Ligand Effects in the Prostate-Specific G-Protein Coupled Receptor (PSGR). Sci. Rep. 2017, 7, 16007. [CrossRef]

3. Smyth, H.; Cozzolino, D. Instrumental Methods (Spectroscopy, Electronic Nose, and Tongue) As Tools To Predict Taste and Aroma in Beverages: Advantages and Limitations. Chem. Rev. 2013, 113, 1429-1440. [CrossRef]

4. Brattoli, M.; de Gennaro, G.; de Pinto, V.; Loiotile, A.D.; Lovascio, S.; Penza, M. Odour Detection Methods: Olfactometry and Chemical Sensors. Sensors 2011, 11, 5290-5322. [CrossRef]

5. Wasilewski, T.; Gębicki, J.; Kamysz, W. Bioelectronic nose: Current status and perspectives. Biosens. Bioelectron. 2017, 87, 480-494. [CrossRef]

6. Soboleva, O.A.; Protsenko, P.V.; Korolev, V.V.; Viktorova, J.; Yakushenko, A.; Kudla, R.; Gutmann, J.S.; Tsarkova, L.A. Aroma Molecules as Dynamic Volatile Surfactants: Functionality beyond the Scent. ACS Appl. Mater. Interfaces 2019, 11, 40988-40995. [CrossRef] [PubMed]

7. Lewandowski, A.; Szymczyk, K. Adsorption of monoterpene alcohols at the water-air interface. Adsorption 2019, 25, 301-308. [CrossRef]

8. Berg, J.C. An Introduction to Interfaces and Colloids: The Bridge to Nanoscience; University of Washington: Washington, WA, USA, 2009. [CrossRef]

9. Eastoe, J.; Dalton, J.S. Dynamic surface tension and adsorption mechanisms of surfactants at the air-water interface. Adv. Colloid Interface Sci. 2000, 85, 103-144. [CrossRef]

10. Miller, R.; Aksenenko, E.V.; Fainerman, V.B. Dynamic interfacial tension of surfactant solutions. Adv. Colloid Interface Sci. 2017, 247, 115-129. [CrossRef]

11. Thiele, M.J.; Davari, M.D.; Hofmann, I.; Koenig, M.; Lopez, C.G.; Vojcic, L.; Richtering, W.; Schwaneberg, U.; Tsarkova, L.A. Enzyme-Compatible Dynamic Nanoreactors from Electrostatically Bridged Like-Charged Surfactants and Polyelectrolytes. Angew. Chem. Int. Ed. 2018, 57, 9402-9407. [CrossRef]

12. Danov, K.D.; Gurkov, T.D.; Stanimirova, R.D.; Uzunova, R.I. Kinetics of transfer of volatile amphiphiles (fragrances) from vapors to aqueous drops and vice versa: Interplay of diffusion and barrier mechanisms. Colloids Surf. A Physicochem. Eng. Asp. 2021, 126931. [CrossRef]

13. Soboleva, O.A.; Tsarkova, L.A. Surface Properties of Aqueous Solutions of Mixtures of Sodium Dodecyl Sulphate and Linalool under Equilibrium and Dynamic Conditions. Colloid J. 2020, 82, 437-447. [CrossRef]

14. Murphy, R.W.; Zhu, L.; Narsimhan, G.; Jones, O.G. Impacts of Size and Deformability of $\beta$-Lactoglobulin Microgels on the Colloidal Stability and Volatile Flavor Release of Microgel-Stabilized Emulsions. Gels 2018, 4, 79. [CrossRef]

15. Friberg, S.E.; Aikens, P.A. Constant vapor pressure emulsions evaporation: Linalool/water stabilized by Laureth 4 . J. Colloid Interface Sci. 2009, 333, 599-604. [CrossRef]

16. Binks, B.P.; Fletcher, P.D.I.; Holt, B.L.; Beaussoubre, P.; Wong, K. Selective Retardation of Perfume Oil Evaporation from Oil-in-Water Emulsions Stabilized by Either Surfactant or Nanoparticles. Langmuir 2010, 26, 18024-18030. [CrossRef] [PubMed]

17. Qi, N.; Sun, H.; Zhao, H.; Li, Y. Achieving foaming control smartly: Pre-solubilized flavor oil serves as an in situ homogeneous defoamer. Soft Matter 2018, 14, 2059-2067. [CrossRef]

18. Chen, Z.; Zhao, Y.; Zhu, X. Inclusion of Hydrophobic Liquids in Silica Aerogel Microparticles in an Aqueous Process: Microencapsulation and Extra Pore Creation. ACS Appl. Mater. Interfaces 2021, 13, 12230-12240. [CrossRef] 
19. Ly, H.V.; Longo, M.L. The influence of short-chain alcohols on interfacial tension, mechanical properties, area/molecule, and permeability of fluid lipid bilayers. Biophys. J. 2004, 87, 1013-1033. [CrossRef]

20. Pereira, I.; Zielinska, A.; Ferreira, N.R.; Silva, A.M.; Souto, E.B. Optimization of linalool-loaded solid lipid nanoparticles using experimental factorial design and long-term stability studies with a new centrifugal sedimentation method. Int. J. Pharm. 2018, 549, 261-270. [CrossRef]

21. Popadyuk, N.; Popadyuk, A.; Kohut, A.; Voronov, A. Thermoresponsive latexes for fragrance encapsulation and release. Int. J. Cosmet. Sci. 2016, 38, 139-147. [CrossRef]

22. Fieber, W.; Scheklaukov, A.; Kunz, W.; Pleines, M.; Benczédi, D.; Zemb, T. Towards a general understanding of the effects of hydrophobic additives on the viscosity of surfactant solutions. J. Mol. Liq. 2021, 329, 115523. [CrossRef]

23. Penfold, J.; Tucker, I.; Green, A.; Grainger, D.; Jones, C.; Ford, G.; Roberts, C.; Hubbard, J.; Petkov, J.; Thomas, R.K.; et al. Impact of Model Perfumes on Surfactant and Mixed Surfactant Self-Assembly. Langmuir 2008, 24, 12209-12220. [CrossRef] [PubMed]

24. Pleines, M.; Kunz, W.; Zemb, T.; Benczédi, D.; Fieber, W. Molecular factors governing the viscosity peak of giant micelles in the presence of salt and fragrances. J. Colloid Interface Sci. 2019, 537, 682-693. [CrossRef]

25. Tchakalova, V.; Lutz, E.; Lamboley, S.; Moulin, E.; Benczédi, D.; Giuseppone, N.; Herrmann, A. Design of Stimuli-Responsive Dynamic Covalent Delivery Systems for Volatile Compounds (Part 2): Fragrance-Releasing Cleavable Surfactants in Functional Perfumery Applications. Chem.-A Eur. J. 2021, 27, 13468-13476. [CrossRef]

26. Soboleva, O.A.; Gurkov, T.D.; Stanimirova, R.D.; Protsenko, P.V.; Tsarkova, L.A. Volatile aroma surfactants: Evaluation of the adsorption-evaporation behavior under dynamic and equilibrium conditions. 2021; submitted.

27. Rak, D.; Sedlak, M. On the Mesoscale Solubility in Liquid Solutions and Mixtures. J. Phys. Chem. B 2019, 123, 1365-1374. [CrossRef]

28. Miller, R.; Dutschk, V.; Fainerman, V.B. Influence of molecular processes at liquid interfaces on dynamic surface tensions and wetting kinetics. J. Adhes. 2004, 80, 549-561. [CrossRef]

29. Covarrubias-Cervantes, M.; Champion, D.; Debeaufort, F.; Voilley, A. Translational Diffusion Coefficients of Volatile Compounds in Various Aqueous Solutions at Low and Subzero Temperatures. J. Agric. Food Chem. 2005, 53, 6771-6776. [CrossRef] [PubMed] 